\title{
CORRIGENDUM
}

\section{Coral reef invertebrate microbiomes correlate with the presence of photosymbionts}

\author{
David G Bourne, Paul G Dennis, Sven Uthicke, Rochelle M Soo, Gene W Tyson and \\ Nicole Webster
}

The ISME Journal (2013) 7, 1459; doi:10.1038/ismej.2013.71

Correction to: The ISME Journal (2013) 7, 1452-1458; doi:10.1038/ismej.2012.172; published online 10 January 2013

Since the publication of this paper, the authors have become aware of an error in terminology leading to confusion in the definition of 'photosymbiont bearing' and 'non-photosymbiont bearing' invertebrates.

The authors wish to clarify that this manuscript refers only to eukaryotic photosymbionts (Symbiodinium and diatoms). Cyanobacteria were present across most invertebrate species as identified in Figure 1 and are known to be abundant in some ascidians such as Didemnum molle and Lissoclinum patella.

The authors have also become aware of a spelling error within table 1 and also the Supplementary Methods section, regarding 'Diademnum molle'. The correct spelling is 'Didemnum molle'.

The authors would like to apologise for any inconvenience this may have caused. 